\title{
One-pot Procedure to Prepare 2-Pyridil-2-oxazolines
}

\author{
Edison P. Wendler*, Rafaela C. Carmona** and Alcindo A. Dos Santos \\ Institute of Chemistry, University of São Paulo, 05508-000 - São Paulo, SP - Brazil \\ *wendlerep@hotmail.com ** rafacarmona@usp.br
}

Keywords: 2-pyridil-2-oxazolines, chiral ligands, one-pot procedure

\section{INTRODUCTION}

Economical and efficient synthetic design of optically active chiral ligands for highly enantioselective transformations continue to be one of the most challenging tasks in asymmetric synthesis. ${ }^{1}$ The 2-oxazoline ring can be found in biologically active natural products and pharmaceuticals. In addition their chiral derivatives are widely used as ligands or chiral pools in asymmetric synthesis. $^{2}$

There are a myriad of reactions and transformations stereoselectivilly-assisted by chiral oxazolines as for instance lactone synthesis, cyclopropanation, aziridination, Diels-Alder cycloaddition, allylic substitution, among others. ${ }^{3}$

In face of its large application, the development of practical, economically attractive as well as environmental benign methods to prepare 2 oxazolines is constantly desirable. ${ }^{4}$

In this work we describe a one-pot procedure to prepare 2-pyridil-2-oxazolines by reacting 2-cyanopyridine with chiral amino alcohols catalyzed by zinc acetate under pressure.

\section{RESULTS AND DISCUSSION}

Amino alcohols 7-12 were prepared from the corresponding amino acids by known procedure as shown in scheme $1 .^{5}$

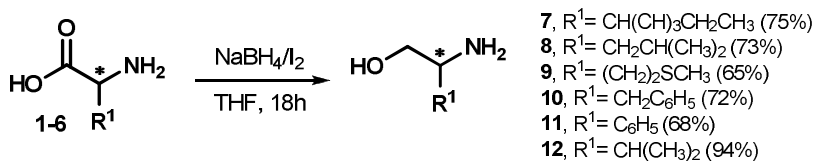

Scheme 1 - Reduction of amino acids.

Amino alcohols derived from terpene ketones 13-16, were prepared by sequential conversion of the ketone into the corresponding diastereoisomeric optically active cyanohydrins followed by reduction with $\mathrm{LiAlH}_{4}$ according scheme $2^{6}$

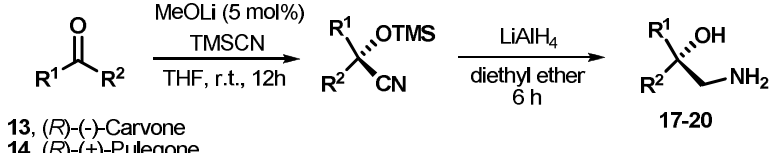

14, $(R)-(+)$-Pulegone

15, $(R)-(+)-$ Camphor

16, $(R)-(-)$-Fenchone

(overall yield range: $77-80 \%$ )

Scheme 2 - Preparation of the amino alcohols.
We found that heating the amino alcohol and 2-cyanopyridine in hexane and catalytic amount (2 mol\%) of zinc acetate, results in the corresponding 2-pyridil-2-oxazoline in reasonable to excellent yield as presented below.
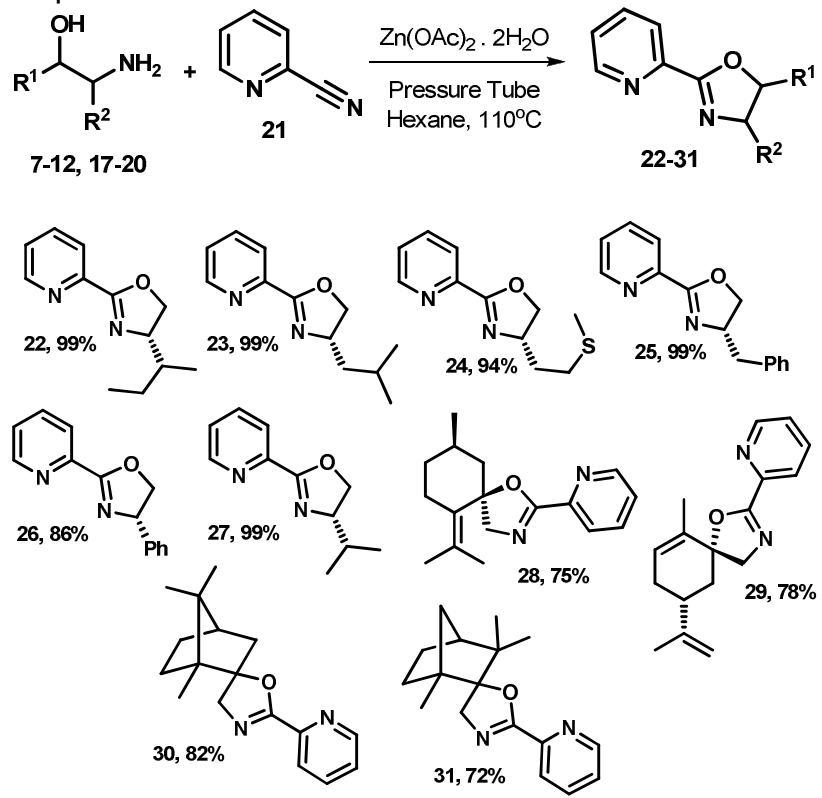

Scheme 3 - Synthesis of 2-pyridil-2-oxazolines

\section{CONCLUSION}

In conclusion, we have developed a straightforward procedure to prepare 2-pyridil-2oxazolines. Afterward, these chiral ligands will be employed as asymmetric inductors for asymmetric synthesis.

\section{ACKNOWLEDGEMENTS

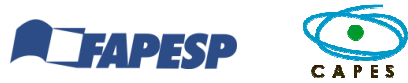 \\ Q $C N P q$}

\section{REFERENCES}

Jacobsen, E. N., Pfaltz, A., Yamamoto, H., Comprehensive Asymmetric Catalysis. Eds; Springer-Verlag: Berlin, 1999.

${ }^{2}$ Ghosh, A. K.; Mathivanan, P.; Cappiello. Tetrahedron Asymm., 1998, 9, 1-45.

${ }^{3}$ De Oliveira, A. R. M.; Simonelli, F.; Marques F. A.; Clososki, G. C.; Oliveira, M. A. F. C. Química Nova 1999, 22, 854-862.

${ }^{4}$ Kempe, K. et al. J. Comb. Chem. 2009, 11, 274-280.

${ }^{5}$ Mckennon, M. J.; Meyers, A. I. J. Org. Chem. 1993, 58, 35683571.

${ }^{6}$ Wilkinson, H. S. et al. Org. Lett., 2001, 3, 553-556. 